\title{
Algunos aspectos sobre el estado de colonización y estado serológico en cerdas vacunadas contra Mycoplasma hyopneumoniae y de sus lechones según el número ordinal de partos ${ }^{\#}$
}

\author{
Some aspects about the colonization and serologic state of Mycoplasma hyopneumoniae \\ vaccinated sows and their piglets by parity distribution
}

\author{
P Tamiozzo ${ }^{\text {a,b* } * \text { A Carranza }}{ }^{\text {a, }}$ J Parada ${ }^{\text {a,c }}$, B Pelliza ${ }^{\text {a }}$, A Ambrogi ${ }^{\text {a }}$ \\ ${ }^{a}$ Grupo Salud Porcina, Departamento Patología Animal, Facultad de Agronomía y Veterinaria, Universidad Nacional de Río Cuarto, \\ Córdoba, Argentina. \\ ${ }^{\mathrm{b}}$ Consejo Nacional de Investigaciones Científicas y Técnicas (CONICET), Argentina. \\ ${ }^{\mathrm{c}}$ Consejo Nacional de Investigaciones Científicas y Técnicas (CONICET), Ministerio de Ciencia y Técnica de la Provincia de \\ Córdoba, Córdoba, Argentina.
}

\begin{abstract}
SUMMARY
The aim of this study was to determine the colonization and serologic state of piglets and sows of different ordinal number of farrowings. Between 78 and 81 sows, multiple-vaccinated against Mycoplasma hyopneumoniae ( $M h$ ), were sampled (from $1^{\text {st }}$ to $9^{\text {th }}$ parity) at day 0 of gestation, 8 weeks of pre-farrowing and post-farrowing, and 163 piglets at two weeks old, taking blood samples (for enzime-linked immunosorbent assay test, ELISA) and nasal swabs (for polymerase chain reaction, PCR). In addition to the percentages of seropositive and PCR positive, other values were obtained to determine the concentration of antibodies and to analyze the dynamics of antibodies in sows and piglets. The percentage of seropositive sows and title values were both high. The same was observed in piglets, allowing to conclude that the multiple vaccinations of the first ones guarantees a high level of antibodies in their offspring, but not $100 \%$. The sows of intermediate parity number showed a higher variability in those values that reflected concentration of antibodies; at day zero of gestation the sows of first farrowing showed these lower values. At post-farrowing, younger sows and their offspring showed the highest percentage of nPCR positive. Sows (and piglets) showed a higher concentration of antibodies when increasing the number of ordinal farrows, although this can be due to vaccination and the repeated exposure of the animals to $M h$ under field conditions.
\end{abstract}

Palabras clave: Mycoplasma hyopneumoniae, hembras, lechones, colonización, ELISA, nPCR.

Key words: Mycoplasma hyopneumoniae, sows, piglets, colonisation, ELISA, nPCR.

\section{INTRODUCCIÓN}

Mycoplasma hyopneumoniae (Mh) es el agente etiológico de la neumonía enzoótica porcina (NEP), una enfermedad respiratoria crónica que afecta principalmente a los cerdos en las etapas de desarrollo-terminación.

La transmisión por contacto con secreciones nasales y la circulación del patógeno puede ocurrir de manera horizontal (de cerdos infectados a cerdos sanos) o de las hembras a sus lechones (Thacker 2006). Para reducir la transmisión de las hembras a los lechones, la vacunación de las mismas (para asegurar una alta concentración de anticuerpos en el calostro) y/o el tratamiento antibiótico tanto de hembras como de lechones (para minimizar la diseminación del patógeno) son medidas de control de la enfermedad usadas frecuentemente (Maes y col 2008).

Se ha sugerido que la prevalencia inicial de la colonización nasal en lechones al destete, utilizando la reacción en cadena de la polimerasa anidada (sus siglas en inglés,

Aceptado: 12.05.2011.

\# Financiado por el Proyecto PICT-O 30511/2005-ANPCyT-FONCyT.

* ptamiozzo@ayv.unrc.edu.ar
nPCR), sería un posible indicador de la diseminación del patógeno por parte de las hembras (Ruiz y col 2003), si bien no está claro el rol de los anticuerpos maternos en la prevención de la colonización de los lechones, pues no se sabe con certeza si la hembra vacunada disemina menor cantidad de $M h$ o la inmunidad pasiva protege a los lechones de la colonización.

Por un lado, la transmisión madre-lechón estaría influenciada por el número ordinal de partos de las mismas. Desde hace tiempo se ha sugerido que las cerdas jóvenes son más propensas a transmitir $M h$ a sus lechones (Goodwin 1965) y si bien recientemente se ha informado lo mismo (Calsamiglia y Pijoan 2000, Fano y col 2006) no existe una determinación taxativa del número ordinal de partos crítico en la transmisión del patógeno.

Por otro lado, las estrategias de vacunación contra $M h$ dependen de diversos factores como el tipo de piara o sistema de producción. En condiciones de campo, la vacunación de las hembras es implementada frecuentemente. Recientemente se ha demostrado que la vacunación de las hembras no influye en la colonización de los lechones, sin embargo aumenta el porcentaje de lechones seropositivos al destete y reduce las lesiones pulmonares compatibles con NEP en matadero (Sibila y col 2007). 
La protección debida a anticuerpos maternos sería suficiente para el control de la infección de $M h$. La inmunidad pasiva es útil en programas de erradicación basados en la despoblación parcial; sin embargo, el resultado de los programas de erradicación dependerían de la cantidad de anticuerpos maternales consumidos por los lechones (Rautiainen y Wallgren 2001).

Pocos estudios han informado sobre los efectos de la vacunación de las hembras en el estado serológico y estado de colonización de los lechones al destete (Ruiz y col 2003, Sibila y col 2007). Sin embargo, la presencia de $M h$ y de anticuerpos en lechones provenientes de madres vacunadas de manera múltiple no ha sido estudiada, tal vez por ser considerado obvio. Esto es importante teniendo en cuenta que la efectividad de la vacuna sería menor en piaras con baja presión de infección (Maes y col 1999).

Finalmente, debido al hecho de que la vacunación de las cerdas no afecta la colonización de los lechones, a los diferentes resultados acerca del estado serológico y estado de colonización de hembras y lechones teniendo en cuenta el número ordinal de partos y a que la efectividad de la vacuna sería menor en piaras con baja presión de infección, los objetivos del presente estudio fueron: 1) Determinar el estado serológico y el estado de colonización de hembras con múltiples vacunas contra $M h$ y lechones según el número ordinal de partos y 2) Analizar la dinámica de la concentración de anticuerpos en las cerdas.

\section{MATERIAL Y MÉTODOS}

\section{LA GRANJA}

Se trabajó en una granja múltiple sitio, con 4.100 madres aproximadamente. Todos los animales reproductores (cerdas, machos y primerizas) recibían como mínimo cinco dosis de vacuna contra $M h$ (RespiSureONE, Pfizer, Argentina). Las hembras eran vacunadas tres semanas preparto y el esquema de vacunación había sido adoptado tres años antes aproximadamente. La granja se consideró de mínima enfermedad, por haber desarrollado un programa de despoblación parcial poco antes del estudio. Los animales enviados a matadero presentaban un bajo porcentaje de lesiones pulmonares compatibles con NEP.

\section{DISEÑO DEL ESTUDIO Y COLECTA DE MUESTRAS}

Se realizó un estudio de cohorte longitudinal. El $n$ de hembras fue obtenido estimando una prevalencia del 10\%, con $95 \%$ de confianza y $5 \%$ de exactitud (Win.Episcope 2.0), ajustando el tamaño del muestreo a la población bajo estudio. Las cerdas fueron elegidas al azar considerando todos los números ordinales de parto (de 1 a 9) en cada muestreo, con una distribución proporcional a la población total de la granja en ese momento. Por la pérdida de algunas muestras, finalmente fueron procesadas 79 , 80 y 79 por serología y 81,80 y 78 por nPCR en los tres muestreos realizados a las hembras, respectivamente (ver más adelante).

Por cada hembra, dos lechones fueron aleatoriamente seleccionados. Las hembras y los lechones fueron identificados con autocrotal. No se realizó cruce de camadas durante el desarrollo del estudio. Por la pérdida de una muestra, se trabajó finalmente con 163 lechones.

Se tomaron muestras de sangre (para serología, sin anticoagulante) e hisopado nasal (poliestireno + viscosa estéril en hembras y aluminio + viscosa estéril en lechones, Deltalab, España) a las hembras en los días cero de gestación, ocho semanas preparto y 2-5 días postparto y a los lechones a las dos semanas de edad. Se tuvo especial cuidado al introducir el hisopo profundamente dentro de la nariz, al retirarlo de la misma y al colocarlo en el interior del tubo con medio de transporte de Amies modificado a fin de evitar la contaminación del mismo.

\section{PROCESAMIENTO DE LAS MUESTRAS}

Serología. Las muestras de sangre fueron centrifugadas a $800 \mathrm{x}$ g por 10 min en centrífuga de sedimentación (Modelo 2036, Rolco, Argentina) y el suero obtenido fue congelado a $-20^{\circ} \mathrm{C}$ hasta su procesamiento. Para detectar la presencia de anticuerpos contra $M h$ se utilizó el kit de ELISA (HerdChek® Mycoplasma hyopneumoniae, IDEXX, Maine, USA) siguiendo las instrucciones del fabricante. Aquellos sueros con valores de densidad óptica (DO) mayores al punto de corte fueron considerados positivos y el resto (dudosos y negativos) como negativos.

Con el fin de obtener una idea aproximada de la concentración de anticuerpos anti- $M h$ se calcularon: el promedio de los valores de la DO, el rango (valor de DO máximo-mínimo), la razón muestra: positivo (M:P=[ $\mathrm{DO}$ de la muestra-DO del control negativo / [DO del control positivo-DO del control negativo]), el título (antilogaritmo del $\log _{10}$ del título) para lo cual debió calcularse primero el $\log _{10}$ del título (1.09 $\left[\log _{10}\right.$ $\mathrm{M}: \mathrm{P}]+3.36$ ), y el valor de grupo de título (teniendo en cuenta la tabla de cuantificación del kit utilizado (IDEXX HerdCheck* Mycoplasma hyopneumoniae $)^{1}$, para comparar la concentración de anticuerpos en las hembras y lechones de acuerdo a los diferentes números ordinales del parto, las hembras en los diferentes momentos de muestreo y en los lechones a las dos semanas de edad.

$n P C R$. Los hisopos nasales fueron resuspendidos en 1 $\mathrm{mL}$ de agua estéril contenida en tubo plástico de $1,5 \mathrm{~mL}$, vortexeados y retirados del tubo. Luego fueron centrifugados a $22.000 \mathrm{x}$ g durante $10 \mathrm{~min}$ a $4^{\circ} \mathrm{C}$ y se trabajó con el sedimento obtenido. El ADN fue extraído utilizando el kit comercial (DNAzol®, Invitrogen ${ }^{\mathrm{TM}}$, CA, USA) de acuerdo a las instrucciones del fabricante. Cada 10 muestras un hisopo vacío fue incluido como control negativo.

\footnotetext{
Brochure, disponible en: http://www.idexx.com/pubwebresources/ pdf/en_us/livestock-poultry/herdchek-mhyo-information-sheet.pdf.
} Accessed march 2010. 
La nPCR fue realizada de acuerdo a previos estudios (Calsamiglia y col 1999) con la única excepción que no se utilizó glicerol al 5\%. Cada cinco muestras se incluyó ADN de Mycoplasma floccculare como control negativo de la amplificación. Como control positivo se utilizó ADN de cultivo puro de $M h$ ubicándolo en la última posición de cada tanda de muestras procesadas (no más de 15 por vez). Para minimizar los riesgos de contaminación, cada uno de los pasos del proceso (extracción de ADN, amplificación y visualización) fue realizado en habitaciones diferentes. El producto amplificado (352 pb) fue corrido en gel de agarosa al $1 \%$ y teñido con bromuro de etidio $(0,5 \mu \mathrm{g} / \mathrm{ml})$ y visualizado con un transiluminador (Luz UV).

\section{ANÁLISIS ESTADÍSTICO}

Para los análisis estadísticos se utilizó el programa EPIDAT (Versión 3.1, Galicia, España). Para analizar el efecto del número ordinal de partos las hembras fueron divididas en los siguientes grupos: A- Bajo número de parto $\left(1^{\text {er }}\right)$, B- Intermedio número de parto $\left(2^{\text {do }}-4^{\text {to }}\right)$, CAlto número de parto $\left(5^{\text {to }}-9^{\text {no }}\right)$.

Se compararon las proporciones de los siguientes parámetros: i) número de hembras seropositivas y nPCR positivas en los diferentes muestreos, ii) número de hembras seropositivas y nPCR positivas de acuerdo al número ordinal de partos en cada uno de los muestreos y iii) número de lechones seropositivos y nPCR positivos según el número ordinal de parto de sus madres.

Se realizó una comparación de medias por un t-test, previa verificación de la normalidad de los datos, de los valores promedio de DO y de las razones M:P de hembras de diferentes números de partos en los distintos muestreos.

Para analizar la relación entre el estado serológico y estado de colonización de la madre y el lechón se usaron tablas de contingencia $(2 \times 2)$ considerando el número ordinal de partos de las cerdas.

\section{RESULTADOS}

El porcentaje de hembras seropositivas fue alto en todos los muestreos (cuadro 1). No hubo diferencia estadísticamente significativa $(\mathrm{P}>0,05)$ entre hembras seropositivas en los diferentes muestreos, ni entre hembras seropositivas con distinto número ordinal de parto a pesar de que se observaron diferentes comportamientos entre los grupos. A saber: en el muestreo del día cero de gestación, los porcentajes de seropositivas fueron aumentando acorde aumentaba el número ordinal de partos. En los siguientes muestreos, hembras de los grupos A y C fueron 100\% seropositivas y fueron las hembras de intermedio número de partos quienes mostraron menor porcentaje.

La misma diferencia en el comportamiento de los resultados se observa en relación al número ordinal de partos con los valores de DO, razón M:P y título (cuadro 2) donde, al día cero de gestación, todos los valores aumentaron de acuerdo al aumento en el número de partos. Esto se ve resaltado por el hecho de que hembras del grupo A mostraron un valor de grupo de títulos de anticuerpos de 3 vs los grupos B y C donde este valor fue de 4 . A las 8 semanas preparto y al postparto, las hembras del grupo $\mathrm{B}$ mostraron los valores más bajos de DO y razón M:P. Los valores de grupos de título fueron de 4 a las 8 semanas preparto y de 5 al postparto, para todas las hembras, más allá del número ordinal de partos. El rango (diferencia entre valor máximo y valor mínimo) de DO fue mayor en hembras del grupo B respecto los otros grupos en los tres muestreos. Sólo hubo diferencia estadísticamente significativa $(\mathrm{P}=0,05)$ entre los promedios de $\mathrm{DO}$ y razón $\mathrm{M}: \mathrm{P}$ en hembras del grupo $\mathrm{B}$ respecto las del grupo A y $\mathrm{C}$ a las 8 semanas preparto y al postparto.

El porcentaje de hembras $\mathrm{nPCR}$ positivas varió de $14 \%$ a $50 \%$ (cuadro 1) en todos los muestreos. Sólo en el muestreo del postparto se encontró diferencia estadísticamente significativa $(P=0,0023)$ entre hembras del grupo A respecto al grupo B (cuadro 1). El mayor porcentaje

Cuadro 1. Número de positivos/muestreados (y porcentaje) para nPCR y ELISA, de las cerdas al día 0 de gestación, a las 8 semanas de preparto y a los 2-5 días postparto y lechones de 2 semanas de edad de acuerdo a la distribución del número ordinal de partos.

Number of positives/sampled (and percentage) by nPCR and ELISA, of sows at 0 day of pregnancy, at 8 weeks pre-farrowing and at 2-5 days post farrowing and 2 week old piglets according to parity distribution.

\begin{tabular}{|c|c|c|c|c|c|c|c|c|}
\hline \multirow{2}{*}{$\begin{array}{l}\text { Grupos según } \\
n \text { ordinal de } \\
\text { partos }\end{array}$} & \multicolumn{2}{|c|}{ Día 0 de gestación } & \multicolumn{2}{|c|}{8 semanas preparto } & \multicolumn{2}{|c|}{ 2-5 días postparto } & \multicolumn{2}{|c|}{$\begin{array}{l}\text { Lechones de } 2 \text { semanas } \\
\text { de edad }\end{array}$} \\
\hline & nPCR & ELISA & nPCR & ELISA & $\mathrm{nPCR}$ & ELISA & nPCR & ELISA \\
\hline A & $2 / 14(14,2)$ & $13 / 14(92,8)$ & $3 / 13(23)$ & $13 / 13(100)$ & $7 / 14 *(50)$ & 13/13 (100) & $7 / 27(25,9)$ & $23 / 27(85,1)$ \\
\hline B & $13 / 39(33,3)$ & $38 / 39(97,4)$ & $17 / 40(42,5)$ & $38 / 40$ (95) & $6 / 40 *(15)$ & $39 / 41(95,1)$ & $17 / 81(20,9$ & $74 / 81(91,3)$ \\
\hline $\mathrm{C}$ & $5 / 28(17,8)$ & $26 / 26(100)$ & $11 / 27(40,7)$ & 27/27 (100) & $6 / 24(25)$ & $25 / 25(100)$ & $6 / 55(10,9)$ & $52 / 55(94,5)$ \\
\hline Total & $20 / 81(24,6)$ & $77 / 79(97,4)$ & $31 / 80(38,7)$ & $78 / 80(97,5)$ & $19 / 78(24,3)$ & $77 / 79(97,4)$ & $30 / 163(18,4)$ & $149 / 163(91,4)$ \\
\hline
\end{tabular}

A- Hembras de bajo número de parto $\left(1^{\mathrm{er}}\right)$, B- Hembras de intermedio número de parto $\left(2^{\mathrm{do}}-4^{\mathrm{to}}\right)$ y $\mathrm{C}$ - hembras de alto número de parto $\left(5^{\text {to }}-9^{\text {no }}\right)$.

A- Sows from low parity number ( $\left.1^{\text {st }}\right)$, B- Sows from low intermediate parity number $\left(2^{\text {nd }}-4^{\text {th }}\right)$ y C- Sows from high parity number $\left(5^{\text {th }}-9^{\text {th }}\right)$.

* Diferencia estadísticamente significativa $(\mathrm{P}=0,0023)$ entre ambos muestreos.

* Statistical significant difference $(\mathrm{P}=0.0023)$ between both samplings. 
Cuadro 2. Valores promedio de densidad óptica [DO], rango (valor DO máximo-mínimo), Razón M: P, título y grupo de título de las hembras (al día 0 de gestación, a las 8 semanas preparto y a los 2-5 días postparto) y de los lechones a las 2 semanas de edad de acuerdo al número ordinal de partos.

Average values of optical density [OD], range (OD maximum value- minimum), S:P ratio, titer and antibody titer groups of sows (at 0 days of pregnancy, at 8 weeks pre-farrowing and at 2-5 days post-farrowing) and piglets at 2 weeks old according to parity distribution.

\begin{tabular}{|c|c|c|c|c|}
\hline & \multirow{2}{*}{ Valor } & \multicolumn{3}{|c|}{ Grupos según número ordinal de partos } \\
\hline & & $\mathrm{A}\left(1^{\mathrm{ro}}\right)$ & $\mathrm{B}\left(2^{\mathrm{do}}-4^{\text {to }}\right)$ & $C\left(5^{\text {to }}-9^{\text {no }}\right)$ \\
\hline \multirow{4}{*}{ 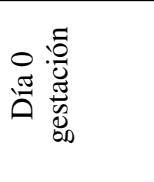 } & Prom DO (rango) & $0,738(0,644)$ & $0,787(1,03)$ & $0,819(0,66)$ \\
\hline & Razón M:P & 1,490 & 1,612 & 1,690 \\
\hline & Título & 3539 & 3854 & 4055 \\
\hline & Grupo de título & 3 & 4 & 4 \\
\hline \multirow{4}{*}{$\begin{array}{l}\dot{0} \\
\dot{D} \\
\infty \\
\infty \\
\infty\end{array}$} & Prom DO (rango) & $0,895(0,901)$ & $0,750 *(0,906)$ & $0,799(0,886)$ \\
\hline & Razón M:P & 1,875 & 1,521 & 1,641 \\
\hline & Título & 4549 & 3614 & 3926 \\
\hline & Grupo de título & 4 & 4 & 4 \\
\hline \multirow{4}{*}{ 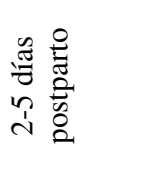 } & Prom DO (rango) & $1,141(0,599)$ & $0,998 *(0,996)$ & $1,019(0,756)$ \\
\hline & Razón M:P & 2,477 & 2,128 & 2,180 \\
\hline & Título & 6151 & 6039 & 5357 \\
\hline & Grupo de título & 5 & 5 & 5 \\
\hline \multirow{2}{*}{$\begin{array}{c}\text { Promedio } \\
\text { Hembras }\end{array}$} & Título & 4756 & 4502 & 4446 \\
\hline & Grupo de título & 4 & 3 & 4 \\
\hline \multirow{4}{*}{ 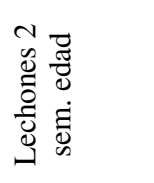 } & Prom DO (rango) & $0,727(1,262)$ & $0,778(1,284)$ & $0,846(1,389)$ \\
\hline & Razón M:P & 1,584 & 1,716 & 1,890 \\
\hline & Título & 3784 & 4130 & 4581 \\
\hline & Grupo de título & 4 & 4 & 4 \\
\hline
\end{tabular}

A- Hembras de bajo número de parto $\left(1^{\mathrm{er}}\right)$, B- Hembras de intermedio número de parto $\left(2^{\text {do }}-4^{\text {to }}\right)$ y C- hembras de alto número de parto $\left(5^{\text {to }}-9^{\text {no }}\right)$. A- Sows from low parity number $\left(1^{\text {st }}\right)$, B- Sows from low intermediate parity number $\left(2^{\text {nd }}-4^{\text {th }}\right)$ y C-Sows from high parity number $\left(5^{\text {th }}-9^{\text {th }}\right)$. * Diferencia estadísticamente significativa $(\mathrm{P}=0,05)$ entre $\mathrm{A}, \mathrm{B}$ y $\mathrm{C}$.

* Statistical significant difference $(\mathrm{P}=0.05)$ among $\mathrm{A}, \mathrm{B}$ and $\mathrm{C}$.

promedio de hembras nPCR positivas fue hallado a las 8 semanas preparto, aunque hubo diferencias entre los diferentes grupos. A saber: en los muestreos del día 0 de gestación y a las 8 semanas preparto, las hembras del grupo B mostraron los mayores porcentajes de nPCR positivas, mientras que en el muestreo del postparto las que mostraron ese mayor porcentaje fueron hembras del grupo A.

El porcentaje de lechones seropositivos varió entre $85,1 \%$ y $94,5 \%$. No hubo diferencia estadísticamente significativa $(\mathrm{P}>0,05)$ entre el número de lechones seropositivos según el número ordinal de parto de sus madres, ni entre lechones nPCR positivos según el mismo parámetro. $\mathrm{Al}$ igual que las hembras al día cero de gestación, tanto los porcentajes de seropositivos como los valores promedios de DO, razón M:P y título aumentaron de acuerdo al número ordinal de parto de sus madres (cuadro 2) aunque el valor de grupo de título fue siempre de 4. Lo contrario ocurrió con los porcentajes de nPCR positivos que fueron decreciendo a medida que aumentaba el número ordinal de parto de sus madres (cuadro 1).

No hubo diferencia estadísticamente significativa entre el estado serológico o de colonización de las hembras y los lechones. Ciento cuarenta y cinco lechones seropositivos (sobre 149; 97,3\%) provenían de madres seropositivas, siendo 52/55 (94,5\%) hijos de hembras de alto número de partos, 70/75 (93,3\%) de hembras de intermedio número de partos y $23 / 27(85,2 \%)$ de hembras de bajo número de partos.

Del total de lechones hijos de madres seropositivas (157), treinta fueron nPCR positivos (19\%), siendo $7 / 27(25,9 \%)$ hijos de hembras de bajo número de parto, $17 / 75(22,6 \%)$ hijos de hembras de intermedio número de partos y 6/55 (11\%) de hembras de alto número de partos (cuadro 3).

Solo $7 / 30$ lechones nPCR positivos $(23,3 \%)$ provenían de madres nPCR positivas, siendo 5 de ellos (71\%) hijos de hembras de bajo número de partos (cuadro 3). No hubo lechones nPCR positivos de madres seronegativas.

\section{DISCUSIÓN}

El porcentaje de hembras seropositivas fue más alto a los obtenidos en estudios previos donde las hembras eran vacunadas por primera vez, dos veces antes del parto (Ruiz y col 2003, Sibila y col 2007). A pesar de que no hubo diferencia estadísticamente significativa entre hembras 
Cuadro 3. Resultados de ELISA y nPCR de los lechones a 2 semanas de edad, teniendo en cuenta el estado serológico y de colonización de las cerdas a los 2-5 días postparto según la distribución del número ordinal de partos.

ELISA and nPCR results of piglets at 2 weeks of age, taking into account the serologic and colonisation state of sows at 2-5 days postfarrowing according their parity distribution.

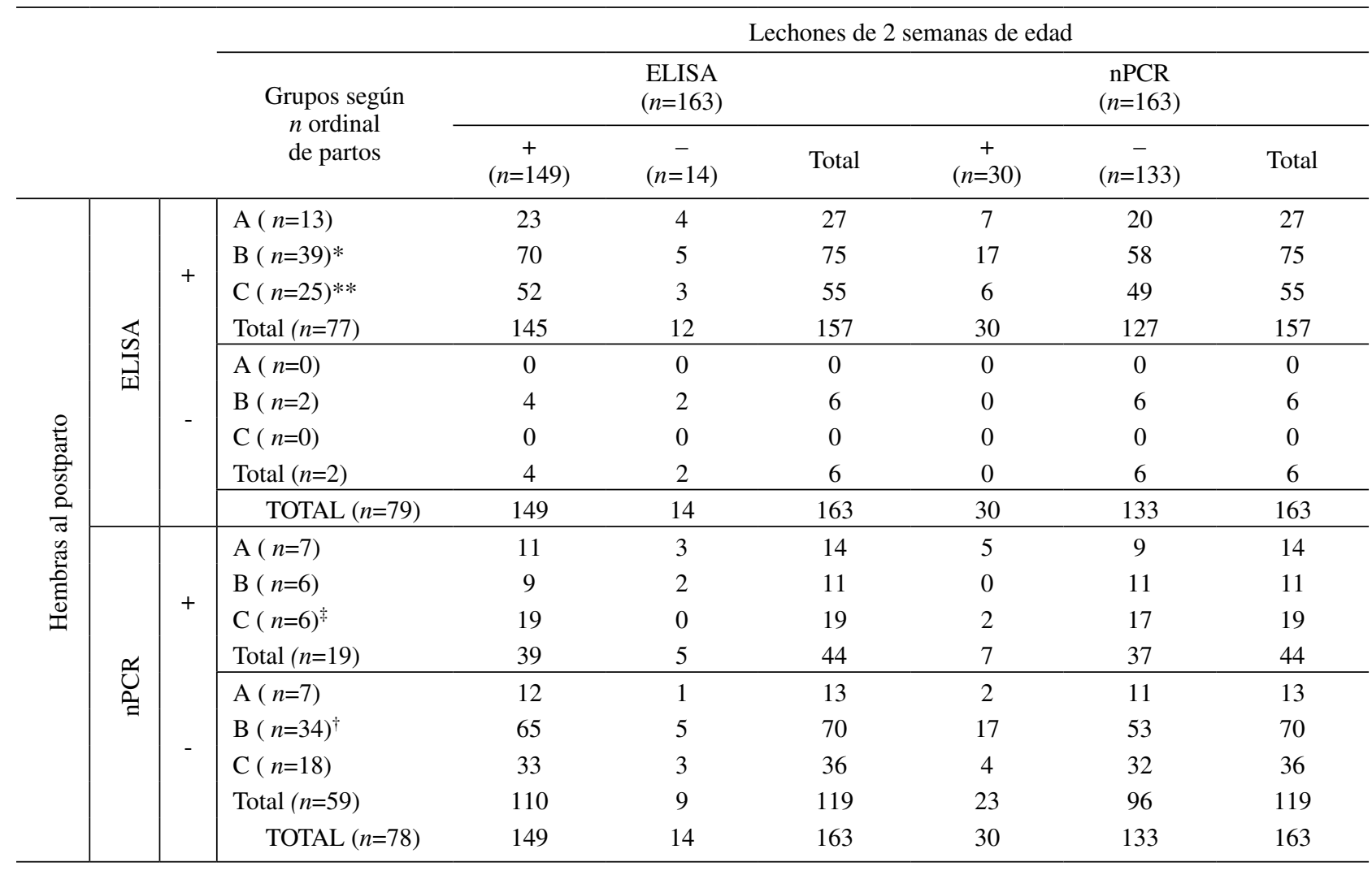

A- Hembras de bajo número de parto $\left(1^{\text {er }}\right)$, B- Hembras de intermedio número de parto $\left(2^{\text {do }}-4^{\text {to }}\right)$ y C- hembras de alto número de parto $\left(5^{\text {to }}-9^{\text {no }}\right)$.

A- Sows from low parity number $\left(1^{\text {st }}\right)$, B- Sows from low intermediate parity number $\left(2^{\text {nd }}-4^{\text {th }}\right)$ y C- Sows from high parity number $\left(5^{\text {th }}-9^{\text {th }}\right)$.

* En una muestra se consideró el resultado de ELISA de muestreo anterior (8 semanas pre-parto) debido a la pérdida del suero del muestreo postparto.

** En dos muestras se consideraron los resultados de ELISA de muestreo anterior (8 semanas preparto) debido a la pérdida del suero del muestreo postparto.

‡ En 3 muestras se consideraron los resultados de nPCR del muestreo anterior (8 semanas preparto) debido a la pérdida del ADN del muestreo post-parto.

$\dagger$ En una muestra se consideró el resultado de nPCR del muestreo anterior (8 semanas preparto) debido a la pérdida del ADN del muestreo postparto.

* In 1 sample was considered the ELISA result of previous sampling ( 8 weeks pre-farrowing) due to loss of a serum of post-farrowing sampling.

** In 2 samples were considered the ELISA results of previous sampling ( 8 weeks pre-farrowing) due to loss of a serum of post-farrowing sampling.

* In 3 samples were considered the nPCR results of previous sampling (8 weeks pre-farrowing) due to loss of a DNA of post-farrowing sampling.

$\dagger \quad$ In 1 sample was considered the nPCR result of previous sampling ( 8 weeks pre-farrowing) due to loss of a DNA of post-farrowing sampling.

de los diferentes muestreos, ni entre hembras con distinto número ordinal de parto, hubo hembras seronegativas.

La presencia de estas hembras seronegativas y los diferentes comportamientos entre los grupos en los distintos muestreos podrían explicarse por el hecho de que el kit de ELISA utilizado no es $100 \%$ sensible (pudiendo dar falsos negativos; Erlandson y col 2005), a que la vacuna no es $100 \%$ efectiva (Giesecke 2002), a distintas respuestas a la vacunación por parte de los animales o a la generación de respuesta inmune celular a la vacuna (Thacker y col 1998) ya que se ha demostrado que la seroconversión inducida al utilizar bacterinas comerciales, es entre el 30\% al 100\% (Mattsson y col 1995, Thacker y col 1998).
Estas diferencias, sumadas al hecho de que en hembras del grupo $\mathrm{B}$ el rango de la DO fue mayor en todos los muestreos respecto a hembras de los otros grupos, y a que en el muestreo del día cero de gestación el valor del grupo de título para hembras del grupo A fue menor al resto, es interesante ya que refuerza la idea previa de que la población de hembras en una piara no es homogénea, sino un conjunto de subpoblaciones con diferente estado inmune, acordando con estudios previos (Dee 1996).

La falta de evidencia estadísticamente significativa no nos permitió establecer taxativamente la relación entre el estado serológico y el número ordinal de partos de las hembras. 
Se ha sugerido que hacia el postparto las hembras se vuelven más susceptibles a la infección por $M h$ porque los anticuerpos protectores son transferidos desde la sangre hacia la glándula mamaria durante el último mes de gestación (Wallgren y col 1998), pero bajo las condiciones de este estudio a las 8 semanas preparto el porcentaje promedio de hembras seropositivas fue el más alto y los otros valores (DO, razón M:P, título y grupo de título) no demostraron caída, lo que podría deberse a que en el momento de dicho muestreo los anticuerpos no estaban siendo transferidos hacia la glándula mamaria aún o al hecho de que las hembras estaban hiperinmunizadas.

En el muestreo postparto, el promedio total de valores de DO así como también la razón M:P, título y grupo de título, aumentaron. Este incremento en los niveles de anticuerpos podría deberse a la respuesta a la vacunación, ya que las cerdas se vacunaron aproximadamente 3 semanas antes de parir. Aunque también podría tratarse de una seroconversión debido a una infección natural, que puede tardar de 4 a 9 semanas (Sitjar y col 1996) o más teniendo en cuanta la baja la presión de infección asumida en el presente estudio.

En todos los muestreos, la razón M:P fue más baja que otras obtenidas al postparto, en suero de cerdas vacunadas por vez primera, dos semanas antes del parto (Martelli y col 2006), provenientes de una piara con antecedentes de $M h$. Esto es interesante porque quizás en ese estudio (Martelli y col 2006) la respuesta a la vacuna fue más exacerbada y en el presente estudio, dada la baja presión de infección debida al programa hiperinmunización aplicado desde hace tiempo y al programa de despoblación parcial llevado a cabo, el comportamiento de la respuesta a la vacunación fue diferente de acuerdo a los métodos de detección utilizados.

En el muestreo del día cero de gestación de las cerdas $\mathrm{y}$ en el de los lechones (2 semanas de edad), los valores promedio de DO, razón M:P y títulos se incrementaron acorde al número ordinal de partos, lo que junto con el alto porcentaje de cerdas seropositivas en el grupo $\mathrm{C}$ (alto número de partos), sugieren que el aumento de la concentración de anticuerpos maternos quizás podría deberse tanto al esquema de hiperinmunización implementado en la granja, como también la exposición repetida de las cerdas al $M h$ en condiciones de campo, siendo las cerdas más viejas las que mayor concentración de anticuerpos presentaron.

Sin embargo, en el muestreo de las 8 semanas preparto las cerdas de intermedio número de partos $\left(2^{\mathrm{do}}\right.$ a $\left.4^{\text {to }}\right)$ mostraron los valores más bajos (promedio de DO, razón M: P, título y grupo de título) respecto a hembras de bajo y alto número de partos. Esto, sumado al hecho de que las hembras del grupo B mostraron el mayor rango de DO en todos los muestreos puede deberse a que estas hembras pertenecen a una subpoblación con mayor variabilidad en la concentración de anticuerpos, ya que tanto las hembras más jóvenes, al enfrentarse por primera vez con el agente como las hembras más viejas, que han estado expuestas por largo tiempo al agente, además de las vacunaciones, presentan una concentración de anticuerpos más alta.

Los resultados de nPCR señalan la presencia del patógeno en la piara. Nosotros asumimos que el Mh está presente, pero en cantidad insuficiente para causar enfermedad ya que no había tos (datos inéditos) a pesar de que el porcentaje de nPCR positivos es mayor al obtenido en otros estudios (Ruiz y col 2003, Fano y col 2006, Sibila y col 2007) ya que debemos tener en cuenta la capacidad de la PCR de detectar microorganismos viables o no viables y el mayor riesgo de obtener falsos positivos al utilizar una PCR anidada.

Asumiendo que el muestreo postparto es el que mejor representa la relación entre la madre y el lechón, y teniendo en cuenta la evidencia estadísticamente significativa obtenida en los resultados de nPCR de las cerdas de grupo A $v s$ grupo B, se sugeriría que las hembras de primer parto son más propensas a transmitir el $M h$ a sus lechones, ya que también fueron los hijos de esas hembras los que mayor porcentajes de nPCR positivos demostraron si bien no existió en éstos evidencia estadísticamente significativa. Estos resultados concuerdan parcialmente con otros en donde se ha señalado como grupo de riesgo a hembras jóvenes (Goodwin 1965, Calsamiglia y Pijoan 2000, Fano y col 2006), aunque no pudo demostrarse y sigue poco claro cuál es el número de partos crítico en la transmisión del patógeno ya que los diferentes autores consideramos de manera distinta hembras de bajo, intermedio o alto número de partos. Además, en ese muestreo, las hembras de intermedio número de partos fueron las que menores porcentajes de nPCR positivos mostraron, no reflejándose lo mismo en sus lechones. Esto puede deberse a la eliminación intermitente del patógeno (Ruiz y col 2003).

Solamente en dos momentos coincidieron los porcentajes más altos de nPCR positivos y los porcentajes más bajos de seropositivos, en el grupo B de hembras a las 8 semanas preparto y en los lechones. A primera vista, estos resultados sugerirían que un menor nivel de anticuerpos protectores predispone a una mayor diseminación del $M h$ pero sería un error aseverar esto ya que en el resto de los muestreos no hubo tal coincidencia. Esta falta de coincidencia, además del hecho de que no hubo lechones nPCR positivos hijos de madres seronegativas se deba quizás, por un lado, a que, como se dijo anteriormente, los animales no presenten anticuerpos pero sí estén protegidos por inmunidad celular (Thacker y col 1998), y por otro lado a la diseminación intermitente de $M h$, responsable también del comportamiento dispar de los resultados de nPCR entre los grupos (Ruiz y col 2003). Estos dos fenómenos constituyen el principal obstáculo en estudios de este tipo.

Además, al día 0 de gestación, las hembras del grupo A no sólo mostraron el porcentaje más bajo de seropositivos, sino también los valores más bajos de promedio de DO, razón M:P, título y grupo de título de todos los muestreos realizados en las hembras. Esto puede ser explicado por 
el hecho de que los anticuerpos vacunales decayeron, ya que en el primer muestreo las hembras habían sido vacunadas 12 semanas antes y de acuerdo a estudios anteriores (Maes y col 1999) llevado a cabo no en hembras, sino en cerdos en crecimiento, la concentración de anticuerpos sin el efecto "booster" de una infección natural, decaen en 3 meses aproximadamente siendo el grupo de hembras más jóvenes el que más caída de anticuerpos demostró. Sin embargo luego aumentaron, por lo que se trataría de una seroconversión debido a una infección natural o bien debido a la vacunación realizada preparto.

Más del 85\% de los lechones fueron seropositivos, seguramente debido estado serológico de las cerdas. El $97,3 \%$ de los lechones seropositivos procedían de cerdas seropositivas, mostrando una alta tasa de transferencia de anticuerpos maternos. El hecho de que el 100\% de los lechones hijos de hembras seropositivas no fueran seropositivos puede deberse a la vida media de los anticuerpos en el suero de los mismos que varía de 6,5 a 22,5 días (Curtis y Boumer 1972) o a la menor cantidad de calostro ingerido por algunos de ellos.

Teniendo en cuenta la distribución según el numero ordinal de partos, el porcentaje más alto de lechones seropositivos procedían de cerdas del grupo $\mathrm{C}$ (alto número de partos) $94,5 \%$ vs $91,3 \%$ en el grupo B y $85,1 \%$ del grupo A. El promedio de lechones nPCR positivos $(18,4 \%)$ fue superior al informado en estudios previos (Ruiz y col 2003, Sibila y col 2007), a pesar de que las cerdas fueron repetidamente vacunadas. Sólo el 23,3\% de los lechones nPCR positivos provenían de cerdas de nPCR positivas. Siendo el $71 \%$ de esos positivos, hijos de cerdas de bajo número de partos. Esto sugiere que la colonización nasal de los lechones refleja el estado de la colonización de las cerdas $(24,3 \%$ de las cerdas fueron nPCR positivos al postparto). La coincidencia entre el menor porcentaje de seropositivos y el mayor porcentaje de nPCR positivos, en lechones hijos de hembras del grupo A, sugeriría que las cerdas de primer parto son más propensas a transmitir $M h$ a sus lechones, como se señalara anteriormente, pero no existió evidencia significativa.

Como se dijo, no está claro el papel de los anticuerpos maternos en la prevención de la colonización los lechones. Nuestros resultados muestran que no hubo lechones nPCR positivos hijos de madres ELISA negativas y que el 100\% de los lechones nPCR positivos provenían de cerdas ELISA positivas, eso sugiere, como se informó anteriormente (Ruiz y col 2003, Sibila y col 2007), que los anticuerpos maternos no protegen a los lechones de la colonización.

En resumen, bajo las condiciones descritas en este estudio, la múltiple vacunación de las cerdas garantiza un alto nivel de anticuerpos en los lechones, aunque no es $100 \%$. Las cerdas de intermedio número de partos $\left(2^{\mathrm{do}} \mathrm{a} 4^{\text {to }}\right)$ presentaron una mayor variabilidad en aquellos valores que reflejan la concentración de anticuerpos. Al postparto las hembras más jóvenes y su descendencia mostraron los mayores porcentajes de nPCR positivos. Si bien las cerdas, al aumentar el número ordinal de partos, tienen mayor concentración de anticuerpos (y sus lechones), esto puede deberse tanto a la vacunación como a la exposición repetida de cerdas al $M h$ en condiciones de campo o seguramente a ambas.

\section{RESUMEN}

Para determinar el estado de colonización y el estado serológico de lechones y de cerdas de diferente número ordinal de partos, entre 78 y 81 hembras vacunadas de manera múltiple contra Mycoplasma hyopneumoniae $(M h)$ fueron muestreadas (de $1^{\mathrm{er}}$ a $9^{\text {no }}$ parto) al día 0 de gestación, a las 8 semanas de preparto y al postparto y 163 lechones a las dos semanas de edad, tomando muestras de sangre (para enzimoinmuno ensayo, ELISA) e hisopados nasales (para reacción en cadena de polimerasa, PCR). Además de los porcentajes de seropositivos y PCR positivos, se calcularon otros valores para determinar la concentración de anticuerpos y así analizar la dinámica de los anticuerpos en hembras y lechones. El porcentaje de cerdas seropositivas fue alto, al igual que los valores de título. Lo mismo se observó en los lechones, por lo que se concluyó que la múltiple vacunación de las primeras garantiza un alto nivel de anticuerpos en sus crías, aunque no es del $100 \%$. Las cerdas de intermedio número de partos presentaron una mayor variabilidad en aquellos valores que reflejan la concentración de anticuerpos; siendo al día cero de gestación las hembras de primer parto las que mostraron estos valores más bajos. Al postparto las hembras más jóvenes y su descendencia mostraron los mayores porcentajes de nPCR positivos. $\mathrm{Si}$ bien las cerdas (y los lechones), al aumentar el número ordinal de partos, presentaron una mayor concentración de anticuerpos, esto puede deberse tanto a la vacunación como a la exposición repetida de los animales al $M h$ en condiciones de campo.

\section{REFERENCIAS}

Calsamiglia M, C Pijoan, A Trigo. 1999. Applications of a nested- polymerase chain reaction assay to detect Mycoplasma hyopneumoniae from nasal swabs. $J$ Vet Diag Invest 1, 246-251.

Calsamiglia M, C Pijoan. 2000. Colonization state and colostral immunity to Mycoplasma hyopneumoniae of different parity sows. Vet Rec 146, 530-532.

Curtis J, J Bourne. 1972. Half-lives of immunoglobulins IgG, IgA and IgM in the serum of new born pigs. Immun 24, 147-155.

Dee S. 1996. The porcine respiratory disease complex: are subpopulations important? J Swine Health Prod 4,147-149.

Erlandson KR, RB Evans, BJ Thacker, MW Wegner, EL Thacker. 2005. Evaluation of three serum antibody enzyme-linked immunosorbent assays for Mycoplasma hyopneumoniae. J Swine Health Prod 13, 198-203

Fano E, C Pijoan, S Dee, M Torremorell. 2006. Assessment of the effect of sow parity on the prevalence of Mycoplasma hyopneumoniae in piglets at weaning. Proceedings of the $19^{\text {th }}$ IPVS Congress, Copenhagen, Denmark.

Giesecke J. 2002. The epidemiology of vaccination In: Arnold E (ed). Modern infectious disease epidemiology. Chapter 19. $2^{\text {nd }}$ ed. London, UK, Pp 226-240.

Goodwin RFW. 1965. The phenomenon of suppressed respiratory disease in the litters of older sow. Vet Rec 77, 383-387.

Maes D, H Deluyker, M Verdonck, F Castryck, C Miry, B Vrijens, W Verbeke, J Viaene, A De Kruif. 1999. Effect of vaccination against Mycoplasma hyopneumoniae in pig herds with an all-in/all-out production system. Vac 17, 1024-1034.

Maes D, J Segales, T Meyns, M Sibila, M Pieters, F Haesebrouck. 2008. Control of Mycoplasma hyopneumoniae infections in pigs. Vet Microbiol 126, 297-309.

Martelli P, M Terreni, S Guazzetti, S Cavirani. 2006. Antibody response to Mycoplasma hyopneumoniae infection in vaccinated pigs with or 
without maternal antibodies induced by sow vaccination. J Vet Med Serie B Infect Diseases and Vet Public Health 53, 229-33.

Mattsson J, K Bergstrom, P Wallgren, K Johansson. 1995. Detection of Mycoplasma hyopneumoniae in nose swabs from pigs by in vitro amplification of the 16SrRNA gene. J Clin Microbiol 33, 893-897.

Rautiainen E, P Wallgren. 2001. Aspects of the transmission of protection against Mycoplasma hyopneumoniae from Sow to Offspring. $J$ Vet Med Series B 48, 55-65.

Ruiz A, V Utrera, C Pijoan. 2003. Effect of Mycoplasma hyopneumoniae sow vaccination on piglets colonization at weaning. J Swine Health Prod 11, 131-135.

Sibila M, R Bernal, D Torrents, P Riera, D Llopart, M Calsamiglia, J 2007. Effect of sow vaccination against Mycoplasma hyopneumoniae on sow and piglet colonization and seroconversion, and pig lung lesions at slaughter. Vet Microbiol 127, 165-170.
Sitjar M, E Noyes, JM Moreso, X Simon, C Pijoan. 1996. Relationships among seroconversion to Mycoplasma hyopneumoniae, lung lesions and production parameters in pigs. J Swine Health Prod 4, 273-277.

Thacker E, B Thacker, TB Boetteter, H Jayappa.1998. Comparison of antibody production, lymphocyte stimulation and protection induced by four commercial Mycoplasma hyopneumonie bacterins. J Swine Heath Prod 6, 107-112.

Thacker E. 2006. Mycoplasmal diseases. In: Straw BE, Zimmerman JJ, D'Allaire S, Taylor DJ (eds) Diseases of Swine. $9^{\text {th }}$ ed. Blackwell Publishing Ltd., Oxford, UK, Pp 701-717.

Wallgren P, G Bölske, S Gustafsson, S Mattsson, C Fossum.1998. Humoral immune response to Mycoplasma hyopneumoniae in sows and offspring following an outbreak of mycoplasmosis. Vet Microbiol 60, 193-205. 